\title{
Analisis Kinerja Wireless Access Point Menggunakan Wifi Monitoring Tools Berbasis Raspberry Pi 3
}

\author{
Ganner Antero"), Abdul Rasyid ${ }^{2)}$, Martono Dwi Atmaja ${ }^{3)}$ \\ ${ }^{1,3}$ Program Studi Jaringan Telekomunikasi Digital, \\ ${ }^{2}$ Program Studi Teknik Telekomunikasi, \\ Jurusan Teknik Elektro, Politeknik Negeri Malang, Indonesia \\ 1.gannerantero@gmail.com, ${ }^{2}$ irrasmt@gmail.ac.id, ${ }^{3}$ martono.dwi@polinema.com
}

\begin{abstract}
Mini computers are now advanced enough to be used in various fields. One of the mini computers that used is the Raspberry Pi 3. The Raspberry Pi 3 is a mini computer that has a feature for a wireless LAN. The wireless LAN feature on a mini computer can be used as a Wireless Access Point. The Raspberry Pi 3 can be an alternative to Wireless Access Point. However, mini computers have different capabilities with Wireless Access Points in general because they have different specifications. The purpose of this study was to determine the performance of the Raspberry Pi 3 based Wireless Access Point. The Raspberry Pi 3 is connected to a laptop that already connected to the internet via a LAN cable. Raspberry Pi 3 is configured as a Wireless Access Point (WAP) and programmed for data retrieval and monitoring in the form of traffic and user information displayed in a web display. In this study, the Raspberry Pi 3 was tested as a Wireless Access Point. The ability of the Raspberry Pi 3 as a Wireless Access Point is greatly influenced by the traffic carried out by the user. According to the test results, the Raspberry Pi 3 as a Wireless Access Point has a maximum limit of 13 users with high traffic loads, 17 users with medium loads and 27 with low loads. This shows that the Raspberry Pi 3 is worthy of being used as a Wireless Access point on a small scale.
\end{abstract}

Keywords - Wireless Access Point, Raspberry Pi 3

Abstrak - Komputer mini sekarang cukup maju hingga dapat dimanfaatkan dalam berbagai bidang. Salah satu komputer mini yang banyak digunakan adalah Raspberry Pi 3. Raspberry Pi 3 adalah salah satu komputer mini yang memiliki fitur berupa wireless LAN. Fitur wireless LAN pada komputer mini dapat dimanfaatkan sebagai Wireless Access Point. Sehingga Raspberry Pi 3 dapat menjadi alternatif Wireless Access Point. Namun komputer mini mempunyai kemampuan yang berbeda dengan Wireless Access Point pada umumnya karena mempunyai spesifikasi yang berbeda. Tujuan dari penelitian ini adalah untuk mengetahui kinerja dari Wireless Access Point yang berbasis Raspberry Pi 3. Raspberry Pi 3 dihubungkan dengan laptop yang sudah terhubung dengan internet melalui kabel LAN dengan tujuan agar Raspberry Pi 3 dapat terhubung ke internet. Raspberry Pi 3 dikonfigurasikan sebagai Wireless Access Point (WAP) dan diprogram untuk pengambilan data dan monitoring yang berupa trafik dan informasi user yang ditampilkan dalam tampilan web. Pada penelitian ini telah dilakukan pengujian Raspberry Pi 3 sebagai Wireless Access Point. Kemampuan Raspberry Pi 3 sebagai Wireless Access Point sangat dipengaruhi oleh trafik yang dilakukan oleh user. Menurut hasil pengujian Raspberry Pi 3 sebagai Wireless Access Point memiliki batas maksimum user sejumlah 13 dengan beban trafik yang tinggi, 17 user dengan beban yang sedang dan 27 dengan beban yang rendah. Hal ini menunjukkan bahwa Raspberry Pi 3 layak digunakan sebagai Wireless Access point dalam skala kecil.

Kata kunci-Wireless Access Point, Raspberry Pi 3

\section{PENDAHULUAN}

Perkembangan teknologi komputer mini sudah cukup maju hingga dapat dimanfaatkan dalam berbagai bidang. Salah satu komputer mini yang banyak digunakan adalah Raspberry Pi. Raspberry Pi 3 adalah salah satu komputer mini yang memiliki fitur berupa wireless LAN. Fitur wireless LAN pada komputer mini dapat dimanfaatkan sebagai Wireless Access Point. Sehingga Raspberry Pi 3 dapat menjadi alternatif Wireless Access Point. Namun komputer mini mempunyai kemampuan yang berbeda dengan Wireless Access Point pada umumnya karena mempunyai spesifikasi yang berbeda [1-3].

Wireless Access Point adalah suatu peranti yang memungkinkan peranti nirkabel untuk terhubung ke dalam jaringan dengan menggunakan Wi-Fi, Bluetooth, atau standar lain. Wireless Access Point biasanya tersambung ke suatu router (melalui kabel) sehingga dapat meneruskan data antara berbagai peranti nirkabel (seperti komputer atau mobile equipment atau perangkat cetak) dengan jaringan berkabel pada suatu jaringan $[4,5]$.

Mobile equipment yang sering digunakan untuk komunikasi mendukung komunikasi Wireless Access Point juga banyak diciptakan oleh banyak perusahaan baik dalam frekuensi 2,4 $\mathrm{GHz}$ ataupun $5 \mathrm{GHz}$ dalam bentuk router atau hanya acces point saja [6]. Tapi dari 2 mobile equipment tersebut tidak bisa disetting untuk OS nya dikarenakan untuk rahasia perusahaan sehingga tidak bisa mengurangi atau menambah fitur didalamnya untuk memaksimalkan peformansi.

Karena alasan tersebut mulai dikembangkan beberapa perangkat mini PC yang untuk menggantikan fungsi router ataupun access point tersebut. Misalkan banana pi, orange pi, 
raspberry pi dan lainnya. Salah satu mini PC yang paling handal diantara semua itu adalah raspberry pi. Sudah banyak program untuk mengaktifkan Wireless Access Point namun tidak ada program untuk melakukan monitoring secara langsung pada raspberry pi 3 tersebut [7 - 9].

Permasalahan dan pengetahuan diatas dapat dijadikan sebagai landasan penelitian "Analisis Kinerja Wireless Access Point Menggunakan WiFi Monitoring Tools Berbasis Raspberry Pi 3" dengan harapan analisis yang dihasilkan dapat digunakan sebagai referensi alternatif dari Wireless Access Point.

\section{METODE}

\section{A. Rancangan Penelitian}

Pada rancangan penelitian ini dijelaskan langkah - langkah penelitian secara umum yang menggambarkan tahapan proses penelitian dari awal hingga didapatkan kesimpulan dari penelitian. Rancangan penelitian ditunjukkan pada gambar berikut:

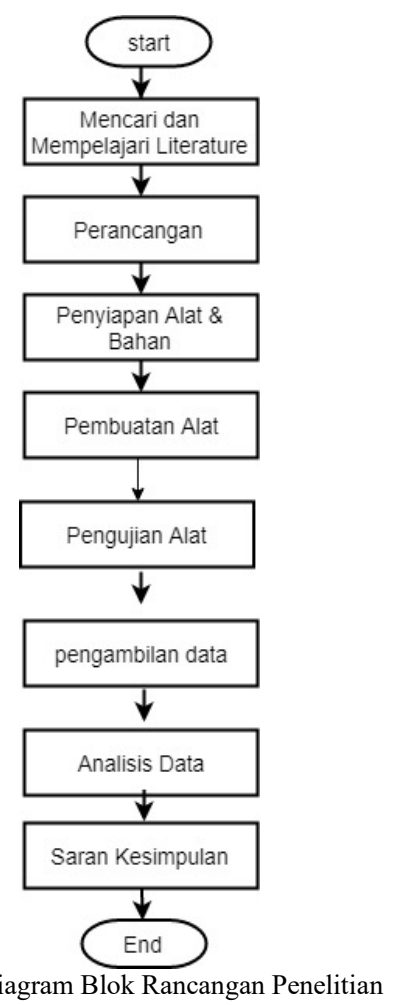

\section{B. Populasi}

Populasi adalah wilayah generalisasi yang terdiri atas obyek/subyek yang mempunyai kualitas dan karakteristik tertentu yang ditetapkan oleh peneliti untuk dipelajari dan kemudian ditarik kesimpulannya. Dalam penelitian ini populasi yang digunakan adalah mahasiswa yang berada pada gedung $\mathrm{AH}$.

\section{Sampel dan Teknik Pengambilan Sampel}

Sampel adalah sebagian dari subyek dalam populasi yang diteliti, yang sudah tentu mampu secara representative dapat mewakili populasinya. Sampel yang digunakan pada penelitian ini adalah mahasiswa yang terhubung dengan jaringan wireless. Mahasiswa menghubungkan perangkat masing-masing ke Access Point dan dilihat berapa jumlah maksimal perangkat yang dapat tersambung.

\section{Data-Data dalam Penelitian}

Data yang diperlukan dalam menunjang penelitian ini adalah Data Primer dan Data Sekunder. Data Primer diperlukan untuk perhitungan dan analisis sedangkan data sekunder diperlukan untuk mendukung data primer dalam mengkaji penelitian yang telah dilakukan. Data Primer : Data yang diperlukan dalam menunjang penelitian ini adalah Data Primer dan Data Sekunder. Data Primer diperlukan untuk perhitungan dan analisis sedangkan data sekunder diperlukan untuk mendukung data primer dalam mengkaji penelitian yang telah dilakukan. Data Sekunder : Merupakan data dari teori penunjang yang serupa dan mendukung penelitian sebagai dasar dalam setiap hasil penelitian seperti buku, jurnal, penelitian terdahulu, artikel, internet dan forum-forum resmi mengenai spesifikasi alat.

\section{E. Perancangan Alat}

Perancangan alat pada penelitian ini merupakan modifikasi komputer papan tunggal (Raspberry Pi 3) yang digunakan sebagai access point. Dalam penelitian ini Raspberry Pi 3 ditambahkan komponen USB Wifi Dongle untuk memperluas jangkauan access point. Access Point mendapatkan jaringan internet melalui kabel LAN yang terhubung laptop [10]. Penggunaan Raspberry Pi 3 sebagai access point dalam rancangan ini digunakan dengan tujuan agar dapat memperoleh hasil data yang dapat diambil secara otomatis. Laptop terkoneksi dengan internet secara wireless dan internet dibagikan melalui kabel LAN.

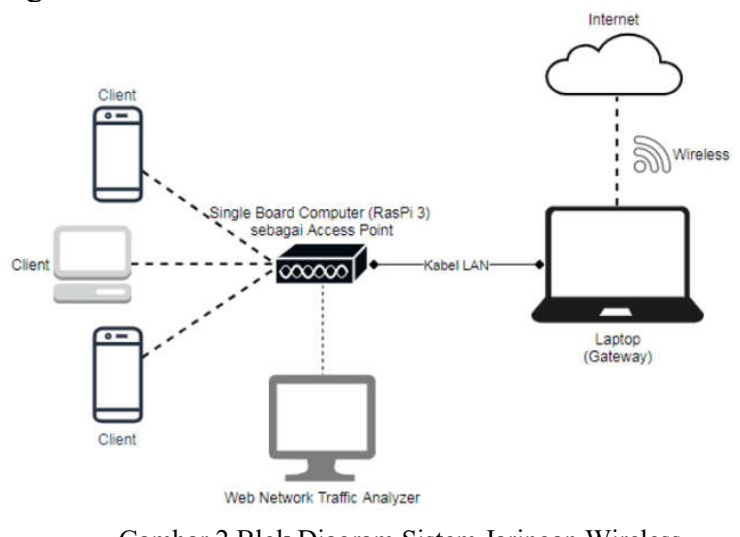

Gambar 2 Blok Diagram Sistem Jaringan Wireless

\section{F. Perancangan Teknik Pengambilan Data}

Teknik pengambilan data trafik yang ditangkap pada setiap ip yang terhubung. Pengambilan data trafik pada setiap ip dilakukan secara realtime. 


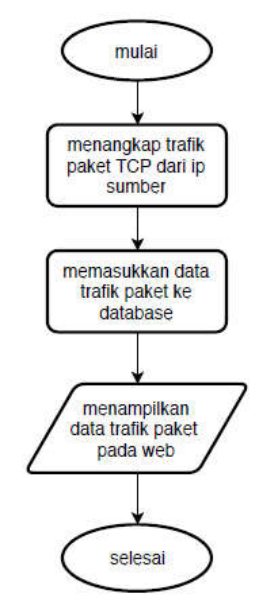

Gambar 3 Diagram Alur Pengambilan Data Trafik

Teknik pengambilan data jumlah pengguna aktif dilakukan dengan menjalankan perintah ping ke semua ip yang pernah terhubung. Bila ping berhasil maka ip tersebut aktif dan terdapat perangkat yang menggunakannya, dan juga sebaliknya jika ping gagal maka ip tersebut tidak aktif dan tidak ada perangkat yang menggunakannya.

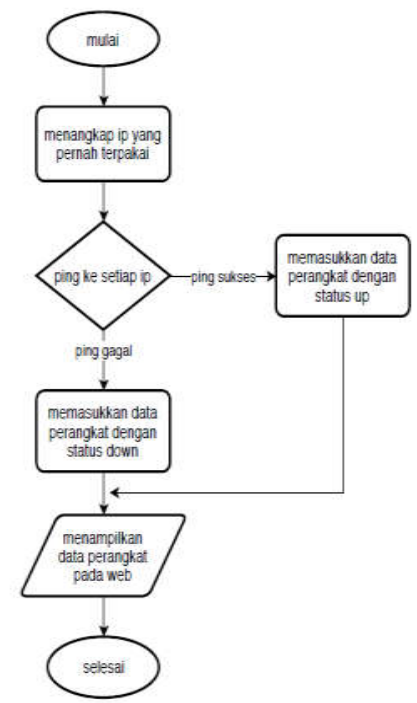

Gambar 4 Diagram Alur Teknik Pengambilan Data Jumlah Pengguna Aktif

\section{G. Teknik Analisis}

Teknik analisis data merupakan suatu langkah yang paling menentukan dari suatu penelitian, karena analisis bertujuan untuk menyimpulkan hasil penelitian. Pada teknik analisis data penelitian, teknik analisis yang digunakan adalah probabilitas Erlang B. Analisis menggunakan probabilitas Erlang B adalah rumus untuk probabilitas pemblokiran yang menggambarkan probabilitas kehilangan panggilan untuk sekelompok sumber daya paralel yang identik (saluran telepon, sirkuit, lalu lintas saluran, atau setara [11-13]).

Dengan menggunakan probablitas Erlang B sebagai referensi analisis, teknik analisis yang digunakan adalah membandingkan jumlah client yang dapat terhubung ke WAP dengan memberikan beban trafik yang berbeda-beda. Beban trafik yang diberikan dibagi menjadi 3 jenis trafik yaitu, trafik dengan aktivitas browsing, video streaming, dan download. Hasil perbandingan akan menunjukkan bagaimana batas kinerja WAP pada kondisi trafik yang berbeda-beda.

\section{H. Penentuan Prosedur dan Parameter}

1) Prosedur konfigurasi Raspberry Pi 3 sebagai Wireless Access Point

2) Prosedur pengambilan data jumlah perangkat aktif dan trafik

3) Parameter, yang digunakan untuk analisis adalah jumlah perangkat aktif, parameter ini digunakan untuk menghasilkan analisis probabilitas erlang yang dapat dilihat pada web dan trafik, parameter ini merupakan jumlah paket yang digunakan oleh ip tertentu untuk mengakses alamat ip tujuan. Paket yang diperolah merupakan paket TCP.

\section{HASIL DAN PEMBAHASAN}

\section{A. Hasil Perancangan Alat}

Single board computer (Raspberry Pi 3) yang telah diprogram untuk menjadi Wireless Access Point.

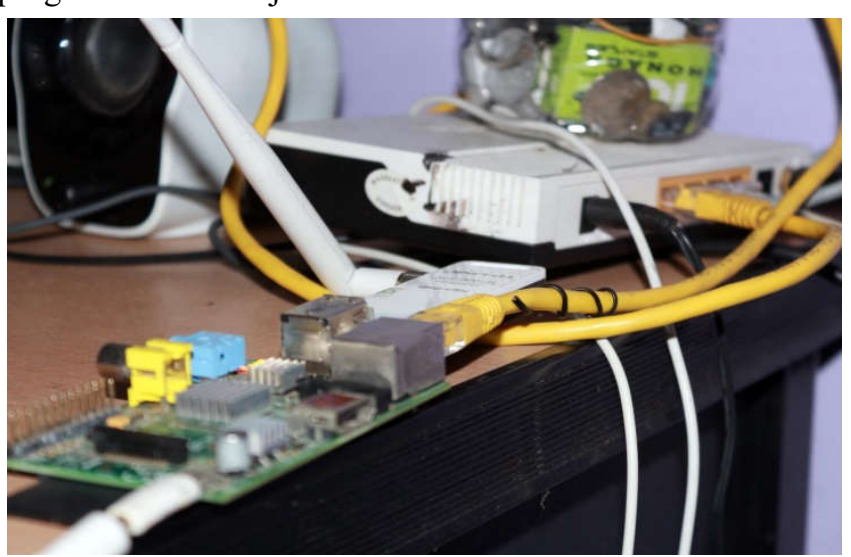

Gambar 5 Hasil Single Board Computer sebagai access point

Program yang digunakan pada Raspberry Pi 3 menggunakan bahasa pemrograman Python [14]. Program ini berfungsi untuk pengambilan data dan monitoring yang berupa trafik dan informasi user dari access point.

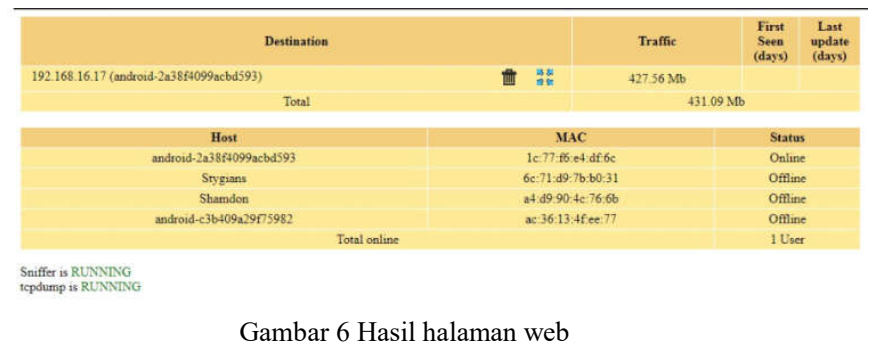

Tampilan web diatas berisi 2 tabel yang berisi informasi data:

1) Destination, merupakan daftar alamat yang diakses oleh user (smartphone dan desktop/laptop). Pada kolom destination tertampil IP user dan detail alamat tujuan user yang dapat diketahui dengan meng-klik

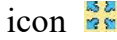

2) Traffic, akumulasi trafik yang digunakan oleh user dalam satuan $(\mathrm{Mb})$ 
3) Host, user yang sedang dan pernah terkoneksi dengan access point

4) MAC, merupakan physical address dari user

5) Status, kondisi user(host) yang terhubung dengan access point

B. Hasil Pengujian Bandwidth Terhadap Wireless Access Point

1) Pengujian pengaruh bandwidth terhadap jumlah user pada aktivitas browsing.

TABEL I

Hasil Pengujian AKTivitas Browsing

\begin{tabular}{|c|c|c|c|}
\hline $\begin{array}{l}\text { Penambahan User } \\
\text { Ke- }\end{array}$ & $\begin{array}{l}\text { Rata-Rata } \\
\text { bandwith } \\
\text { maksimal } \\
\text { User (Mb) }\end{array}$ & Per- & Status \\
\hline 1 & 0.543 & & Terhubung \\
\hline 2 & 0.235 & & Terhubung \\
\hline 3 & 0.114 & & Terhubung \\
\hline 4 & 0.567 & & Terhubung \\
\hline 5 & 0.443 & & Terhubung \\
\hline 6 & 0.105 & & Terhubung \\
\hline 7 & 0.179 & & Terhubung \\
\hline 8 & 0.581 & & Terhubung \\
\hline 9 & 0.384 & & Terhubung \\
\hline 10 & 0.304 & & Terhubung \\
\hline 11 & 0.609 & & Terhubung \\
\hline 12 & 0.437 & & Terhubung \\
\hline 13 & 0.146 & & Terhubung \\
\hline 14 & 0.422 & & Terhubung \\
\hline 15 & 0.387 & & Terhubung \\
\hline 16 & 0.676 & & Terhubung \\
\hline 17 & 0.494 & & Terhubung \\
\hline 18 & 0.502 & & Terhubung \\
\hline 19 & 0.221 & & Terhubung \\
\hline 20 & 0.309 & & Terhubung \\
\hline 21 & 0.211 & & Terhubung \\
\hline 22 & 0.304 & & Terhubung \\
\hline 23 & 0.275 & & Terhubung \\
\hline 24 & 0.216 & & Terhubung \\
\hline 25 & 0.314 & & Terhubung \\
\hline 26 & 0.149 & & Terhubung \\
\hline 27 & 0.219 & & Terhubung \\
\hline 28 & - & & Tidak terhubung \\
\hline 29 & - & & Tidak terhubung \\
\hline 30 & - & & Tidak terhubung \\
\hline
\end{tabular}

Dari Tabel 1 dapat dilihat bahwa semakin banyak jumlah user yang terhubung dengan single board wireless access point persentase nilai GoS semakin besar, hal ini dikarenakan bandwith yang ditawarkan kepada user semakin berkurang [15], bandwidth yang disediakan merupakan bandwidth sharing, dapat dikatakan banyaknya user yang terhubung akan mempengaruhi besar bandwidth maksimal yang dapat digunakan oleh user dan jumlah user yang dapat terhubung ke wireless acess point. Hal ini dapat diketahui pada status user ke 28 - 30 tidak terjadi perubahan nilai bandwith dikarenakan user tidak dapat terhubung ke sistem, yang berarti sistem dalam kondisi jenuh dan tidak dapat menerima penambahan user. Rata penggunaan bandwith untuk 27 user adalah 0.346148148 $\mathrm{Mb}$.

2) Pengujian pengaruh bandwidth terhadap jumlah user pada aktivitas

TABEL II

HASIL PENGUJIAN AKTIVITAS VIDEO STREAMING

\begin{tabular}{|c|c|c|}
\hline $\begin{array}{c}\text { Penambahan User } \\
\text { Ke- }\end{array}$ & $\begin{array}{c}\text { Rata-Rata } \\
\text { bandwith maksimal } \\
\text { Per-User (Mb) }\end{array}$ & Status \\
\hline 1 & 0.427 & Terhubung \\
\hline 2 & 0.648 & Terhubung \\
\hline 3 & 0.449 & Terhubung \\
\hline 4 & 0.556 & Terhubung \\
\hline 5 & 0.774 & Terhubung \\
\hline 6 & 0.691 & Terhubung \\
\hline 7 & 0.511 & Terhubung \\
\hline 8 & 0.801 & Terhubung \\
\hline 9 & 0.546 & Terhubung \\
\hline 10 & 0.389 & Terhubung \\
\hline 11 & 0.491 & Terhubung \\
\hline 12 & 0.476 & Terhubung \\
\hline 13 & 0.597 & Terhubung \\
\hline 14 & 0.501 & Terhubung \\
\hline 15 & 0.473 & Terhubung \\
\hline 16 & 0.771 & Terhubung \\
\hline 17 & 0.769 & Terhubung \\
\hline 18 & - & Tidak terhubung \\
\hline 19 & - & Tidak terhubung \\
\hline 20 & - & Tidak terhubung \\
\hline 21 & - & Tidak terhubung \\
\hline 22 & - & Tidak terhubung \\
\hline 23 & - & Tidak terhubung \\
\hline 24 & - & Tidak terhubung \\
\hline 25 & - & Tidak terhubung \\
\hline 26 & - & Tidak terhubung \\
\hline 27 & - & Tidak terhubung \\
\hline 28 & - & Tidak terhubung \\
\hline 29 & - & Tidak terhubung \\
\hline 30 & - & Tidak terhubung \\
\hline
\end{tabular}

Dari Tabel 2 dapat dilihat bahwa bandwidth yang disediakan merupakan bandwidth sharing, dapat dikatakan banyaknya user yang terhubung akan mempengaruhi besar bandwidth maksimal yang dapat digunakan oleh user dan jumlah user yang dapat terhubung ke wireless acess point. Hal ini dapat diketahui pada status user ke 18 - 30 tidak terjadi perubahan nilai bandwith dikarenakan user tidak dapat terhubung ke sistem, yang berarti sistem dalam kondisi jenuh dan tidak dapat menerima penambahan user. Rata penggunaan bandwith untuk 17 user adalah $0.580588235 \mathrm{Mb}$ 
3) Pengujian pengaruh bandwidth terhadap jumlah user pada aktivitas

TABEL III

Hasil Pengujian AKTivitas Download

\begin{tabular}{|c|c|c|}
\hline $\begin{array}{c}\text { Penambahan User } \\
\text { Ke- }\end{array}$ & $\begin{array}{c}\text { Rata-Rata } \\
\text { bandwith maksimal } \\
\text { Per-User (Mb) }\end{array}$ & Status \\
\hline 1 & 0.779 & Terhubung \\
\hline 2 & 0.871 & Terhubung \\
\hline 3 & 0.611 & Terhubung \\
\hline 4 & 0.905 & Terhubung \\
\hline 5 & 0.917 & Terhubung \\
\hline 6 & 0.561 & Terhubung \\
\hline 7 & 0.843 & Terhubung \\
\hline 8 & 0.957 & Terhubung \\
\hline 9 & 0.858 & Terhubung \\
\hline 10 & 0.695 & Terhubung \\
\hline 11 & 0.714 & Terhubung \\
\hline 12 & 0.638 & Terhubung \\
\hline 13 & 0.644 & Terhubung \\
\hline 14 & 0.774 & Tidak terhubung \\
\hline 15 & 0.691 & Tidak terhubung \\
\hline 16 & 0.511 & Tidak terhubung \\
\hline 17 & 0.801 & Tidak terhubung \\
\hline 18 & - & Tidak terhubung \\
\hline 19 & - & Tidak terhubung \\
\hline 20 & - & Tidak terhubung \\
\hline 21 & - & Tidak terhubung \\
\hline 22 & - & Tidak terhubung \\
\hline 23 & - & Tidak terhubung \\
\hline 24 & - & Tidak terhubung \\
\hline 25 & - & Tidak terhubung \\
\hline 26 & - & Tidak terhubung \\
\hline 27 & - & Tidak terhubung \\
\hline 28 & - & Tidak terhubung \\
\hline 29 & - & Tidak terhubung \\
\hline 30 & - & Tidak terhubung \\
\hline
\end{tabular}

Dari Tabel 3 dapat dilihat bahwa bandwidth yang disediakan merupakan bandwidth sharing, dapat dikatakan banyaknya user yang terhubung akan mempengaruhi besar bandwidth maksimal yang dapat digunakan oleh user dan jumlah user yang dapat terhubung ke wireless acess point. Hal ini dapat diketahui pada status user ke 14 - 30 tidak terjadi perubahan nilai bandwith dikarenakan user tidak dapat terhubung ke sistem, yang berarti sistem dalam kondisi jenuh dan tidak dapat menerima penambahan user. Rata penggunaan bandwith untuk 13 user adalah $0.751176471 \mathrm{Mb}$

\section{Hasil Pengujian Kinerja Maksimal Wireless Access Point}

\section{1) Pengujian Kinerja Wireless Access Point di Hari Pertama}

Tabel 4 merupakan hasil pengambilan data trafik pengguna wireless access point, pada tabel disajikan data rata - rata bandwidth yang digunakan oleh pengguna dan status koneksi.
Dari tabel dapat dilihat bahwa beberapa user memilki trafik yang cukup tinggi seperti user ke 3, 4, 5, 8, 11, 13, 14, 16. User yang memiliki trafik tinggi akan mempengaruhi tingkat kejenuhan dari WAP. Hal ini dikarenakan semakin banyak user yang memiliki trafik tinggi, WAP tersebut akan memiliki jumlah maksimal user yang lebih sedikit. Sehingga dengan jumlah 8 user yang memilki trafik tinggi pada tabel diatas dapat dilihat bahwa sebanyak 18 user dapat terhubung dengan wireless access point pada pengambilan data dihari pertama

TABEL IV

Hasil Pengujian Wireless Access Point Hari Pertama

\begin{tabular}{|c|c|c|}
\hline $\begin{array}{c}\text { Penambahan } \\
\text { User Ke- }\end{array}$ & $\begin{array}{c}\text { Rata-Rata } \\
\text { bandwith } \\
\text { maksimal Per- } \\
\text { User }(\mathrm{Mb})\end{array}$ & Status \\
\hline 1 & 0.103 & Terhubung \\
\hline 2 & 0.345 & Terhubung \\
\hline 3 & 0.532 & Terhubung \\
\hline 4 & 0.498 & Terhubung \\
\hline 5 & 0.684 & Terhubung \\
\hline 6 & 0.233 & Terhubung \\
\hline 7 & 0.181 & Terhubung \\
\hline 8 & 0.698 & Terhubung \\
\hline 9 & 0.213 & Terhubung \\
\hline 10 & 0.122 & Terhubung \\
\hline 11 & 0.466 & Terhubung \\
\hline 12 & 0.344 & Terhubung \\
\hline 13 & 0.714 & Terhubung \\
\hline 14 & 0.541 & Terhubung \\
\hline 15 & 0.349 & Terhubung \\
\hline 16 & 0.771 & Terhubung \\
\hline 17 & 0.583 & Terhubung \\
\hline 18 & 0.147 & Terhubung \\
\hline 19 & - & Tidak Terhubung \\
\hline 20 & - & Tidak Terhubung \\
\hline 21 & - & Tidak Terhubung \\
\hline 22 & - & Tidak Terhubung \\
\hline 23 & - & Tidak Terhubung \\
\hline 24 & - & Tidak Terhubung \\
\hline 25 & - & Tidak Terhubung \\
\hline 26 & - & Tidak Terhubung \\
\hline 27 & - & Tidak Terhubung \\
\hline 28 & - & Tidak Terhubung \\
\hline 29 & - & Tidak Terhubung \\
\hline 30 & - & Tidak Terhubung \\
\hline
\end{tabular}

2) Pengujian Kinerja Wireless Access Point di Hari Kedua TABEL V

Hasil Pengujian Wireless Access Point Hari Kedua

\begin{tabular}{lll}
\hline $\begin{array}{c}\text { Penambahan } \\
\text { User Ke- }\end{array}$ & $\begin{array}{c}\text { Rata-Rata } \\
\text { bandwith } \\
\text { maksimal Per- } \\
\text { User (Mb) }\end{array}$ & Status \\
\hline 1 & 0.287 & Terhubung \\
\hline 2 & 0.678 & Terhubung \\
\hline 3 & 0.349 & Terhubung \\
\hline
\end{tabular}


Jurnal Jaringan Telekomunikasi E-ISSN: 2654-6531 P-ISSN: 2407-0807 Vol. 11, No.4 (2021) 167-174

\begin{tabular}{|c|c|c|}
\hline $\begin{array}{l}\text { Penambahan } \\
\text { User Ke- }\end{array}$ & $\begin{array}{c}\text { Rata-Rata } \\
\text { bandwith } \\
\text { maksimal Per- } \\
\text { User (Mb) }\end{array}$ & Status \\
\hline 4 & 0.867 & Terhubung \\
\hline 5 & 0.761 & Terhubung \\
\hline 6 & 0.624 & Terhubung \\
\hline 7 & 0.372 & Terhubung \\
\hline 8 & 0.328 & Terhubung \\
\hline 9 & 0.275 & Terhubung \\
\hline 10 & 0.256 & Terhubung \\
\hline 11 & 0.329 & Terhubung \\
\hline 12 & 0.539 & Terhubung \\
\hline 13 & 0.308 & Terhubung \\
\hline 14 & 0.612 & Terhubung \\
\hline 15 & 0.322 & Terhubung \\
\hline 16 & 0.627 & Terhubung \\
\hline 17 & 0.348 & Terhubung \\
\hline 18 & 0.258 & Terhubung \\
\hline 19 & 0.201 & Tidak Terhubung \\
\hline 20 & - & Tidak Terhubung \\
\hline 21 & - & Tidak Terhubung \\
\hline 22 & - & Tidak Terhubung \\
\hline 23 & - & Tidak Terhubung \\
\hline 24 & - & Tidak Terhubung \\
\hline 25 & - & Tidak Terhubung \\
\hline 26 & - & Tidak Terhubung \\
\hline 27 & - & Tidak Terhubung \\
\hline 28 & - & Tidak Terhubung \\
\hline 29 & - & Tidak Terhubung \\
\hline 30 & - & Tidak Terhubung \\
\hline
\end{tabular}

Tabel 5 diatas merupakan hasil pengambilan data trafik pengguna wireless access point di hari kedua, pada tabel disajikan data rata - rata bandwidth yang digunakan oleh pengguna dan status koneksi. Dari tabel dapat dilihat bahwa beberapa user memilki trafik yang cukup tinggi seperti user ke $2,4,5,6,12,14,16$. User yang memiliki trafik tinggi akan mempengaruhi tingkat kejenuhan dari WAP. Hal ini dikarenakan semakin banyak user yang memiliki trafik tinggi, WAP tersebut akan memiliki jumlah maksimal user yang lebih sedikit. Sehingga dengan jumlah 7 user yang memilki trafik tinggi pada tabel diatas dapat dilihat bahwa sebanyak 19 user dapat terhubung dengan wireless access point.

3) Pengujian Kinerja Wireless Access Point di Hari Ketiga TABEL VI

Hasil Pengujian Wireless Access Point Hari Ketiga

\begin{tabular}{lll}
\hline $\begin{array}{c}\text { Penambahan } \\
\text { User Ke- }\end{array}$ & $\begin{array}{c}\text { Rata-Rata } \\
\text { bandwith } \\
\text { maksimal Per- } \\
\text { User (Mb) }\end{array}$ & Status \\
\hline 1 & 0.125 & Terhubung \\
\hline 2 & 0.254 & Terhubung \\
\hline 3 & 0.331 & Terhubung \\
\hline 4 & 0.407 & Terhubung \\
\hline 5 & 0.209 & Terhubung \\
\hline
\end{tabular}

\begin{tabular}{|c|c|c|}
\hline $\begin{array}{c}\text { Penambahan } \\
\text { User Ke- }\end{array}$ & $\begin{array}{c}\text { Rata-Rata } \\
\text { bandwith } \\
\text { maksimal Per- } \\
\text { User }(\mathrm{Mb}) \\
\end{array}$ & Status \\
\hline 6 & 0.241 & Terhubung \\
\hline 7 & 0.183 & Terhubung \\
\hline 8 & 0.238 & Terhubung \\
\hline 9 & 0.119 & Terhubung \\
\hline 10 & 0.327 & Terhubung \\
\hline 11 & 0.295 & Terhubung \\
\hline 12 & 0.173 & Terhubung \\
\hline 13 & 0.905 & Terhubung \\
\hline 14 & 0.225 & Terhubung \\
\hline 15 & 0.301 & Terhubung \\
\hline 16 & 0.203 & Terhubung \\
\hline 17 & 0.125 & Terhubung \\
\hline 18 & 0.410 & Terhubung \\
\hline 19 & 0.894 & Terhubung \\
\hline 20 & 0.291 & Terhubung \\
\hline 21 & 0.305 & Terhubung \\
\hline 22 & 0.851 & Terhubung \\
\hline 23 & 0.309 & Terhubung \\
\hline 24 & - & Tidak Terhubung \\
\hline 25 & - & Tidak Terhubung \\
\hline 26 & - & Tidak Terhubung \\
\hline 27 & - & Tidak Terhubung \\
\hline 28 & - & Tidak Terhubung \\
\hline 29 & - & Tidak Terhubung \\
\hline 30 & - & Tidak Terhubung \\
\hline
\end{tabular}

Tabel 6 diatas merupakan hasil pengambilan data trafik pengguna wireless access point, pada tabel disajikan data rata - rata bandwidth yang digunakan oleh pengguna dan status koneksi. Dari tabel dapat dilihat bahwa beberapa user memilki trafik yang cukup tinggi seperti user ke 13, 19, 22. User yang memiliki trafik tinggi akan mempengaruhi tingkat kejenuhan dari WAP. Hal ini dikarenakan semakin sedikit user yang memiliki trafik tinggi, WAP tersebut akan memiliki jumlah maksimal user yang lebih sedikit. Sehingga dengan jumlah 3 user yang memilki trafik tinggi pada tabel diatas dapat dilihat bahwa sebanyak 23 user dapat terhubung dengan wireless access point pada pengambilan data dihari ketiga.

4) Pengujian Kinerja Wireless Access Point di Hari Keempat

TABEL VII

HASIl PENGUJian Wireless ACCESS PoINT HARI KeEMPAT

\begin{tabular}{lll}
$\begin{array}{c}\text { Penambahan } \\
\text { User Ke- }\end{array}$ & $\begin{array}{c}\text { Rata-Rata } \\
\text { bandwith } \\
\text { maksimal Per- } \\
\text { User (Mb) }\end{array}$ & Status \\
\hline 1 & 0.345 & Terhubung \\
\hline 2 & 0.211 & Terhubung \\
\hline 3 & 0.839 & Terhubung \\
\hline 4 & 0.564 & Terhubung \\
\hline 5 & 0.431 & Terhubung \\
\hline
\end{tabular}


Jurnal Jaringan Telekomunikasi E-ISSN: 2654-6531 P-ISSN: 2407-0807 Vol. 11, No.4 (2021) 167-174

\begin{tabular}{|c|c|c|}
\hline $\begin{array}{l}\text { Penambahan } \\
\text { User Ke- }\end{array}$ & $\begin{array}{c}\text { Rata-Rata } \\
\text { bandwith } \\
\text { maksimal Per- } \\
\text { User (Mb) }\end{array}$ & Status \\
\hline 6 & 0.237 & Terhubung \\
\hline 7 & 0.379 & Terhubung \\
\hline 8 & 0.451 & Terhubung \\
\hline 9 & 0.691 & Terhubung \\
\hline 10 & 0.332 & Terhubung \\
\hline 11 & 0.875 & Terhubung \\
\hline 12 & 0.274 & Terhubung \\
\hline 13 & 0.598 & Terhubung \\
\hline 14 & 0.122 & Terhubung \\
\hline 15 & 0.234 & Terhubung \\
\hline 16 & 0.259 & Terhubung \\
\hline 17 & 0.419 & Terhubung \\
\hline 18 & 0.917 & Terhubung \\
\hline 19 & 0.201 & Terhubung \\
\hline 20 & 0.119 & Terhubung \\
\hline 21 & 0.201 & Terhubung \\
\hline 22 & - & Tidak Terhubung \\
\hline 23 & - & Tidak Terhubung \\
\hline 24 & - & Tidak Terhubung \\
\hline 25 & - & Tidak Terhubung \\
\hline 26 & - & Tidak Terhubung \\
\hline 27 & - & Tidak Terhubung \\
\hline 28 & - & Tidak Terhubung \\
\hline 29 & - & Tidak Terhubung \\
\hline 30 & - & Tidak Terhubung \\
\hline
\end{tabular}

\begin{tabular}{|c|c|c|}
\hline $\begin{array}{l}\text { Penambahan } \\
\text { User Ke- }\end{array}$ & $\begin{array}{c}\text { Rata-Rata } \\
\text { bandwith } \\
\text { maksimal Per- } \\
\text { User (Mb) }\end{array}$ & Status \\
\hline 8 & 0.349 & Terhubung \\
\hline 9 & 0.542 & Terhubung \\
\hline 10 & 0.931 & Terhubung \\
\hline 11 & 0.438 & Terhubung \\
\hline 12 & 0.332 & Terhubung \\
\hline 13 & 0.729 & Terhubung \\
\hline 14 & 0.898 & Terhubung \\
\hline 15 & - & Tidak Terhubung \\
\hline 16 & - & Tidak Terhubung \\
\hline 17 & - & Tidak Terhubung \\
\hline 18 & - & Tidak Terhubung \\
\hline 19 & - & Tidak Terhubung \\
\hline 20 & - & Tidak Terhubung \\
\hline 21 & - & Tidak Terhubung \\
\hline 22 & - & Tidak Terhubung \\
\hline 23 & - & Tidak Terhubung \\
\hline 24 & - & Tidak Terhubung \\
\hline 25 & - & Tidak Terhubung \\
\hline 26 & - & Tidak Terhubung \\
\hline 27 & - & Tidak Terhubung \\
\hline 28 & - & Tidak Terhubung \\
\hline 29 & - & Tidak Terhubung \\
\hline 30 & - & Tidak Terhubung \\
\hline
\end{tabular}

Tabel 8 merupakan hasil pengambilan data trafik pengguna wireless access point, pada tabel disajikan data rata - rata bandwidth yang digunakan oleh pengguna dan status koneksi. Dari tabel dapat dilihat bahwa beberapa user memilki trafik yang cukup tinggi seperti user no 1, 2, 3, 4, 6, 9, 10, 13, 14 . User yang memiliki trafik tinggi akan mempengaruhi tingkat kejenuhan dari WAP. Hal ini dikarenakan semakin banyak user yang memiliki trafik tinggi, WAP tersebut akan memiliki jumlah maksimal user yang lebih sedikit. Sehingga dengan jumlah user 9 yang memilki trafik tinggi pada tabel diatas dapat dilihat bahwa sebanyak 14 user dapat terhubung dengan wireless access point pada pengambilan data dihari kelima.

D. Grafik Pengujian Kinerja Wireless Access Point

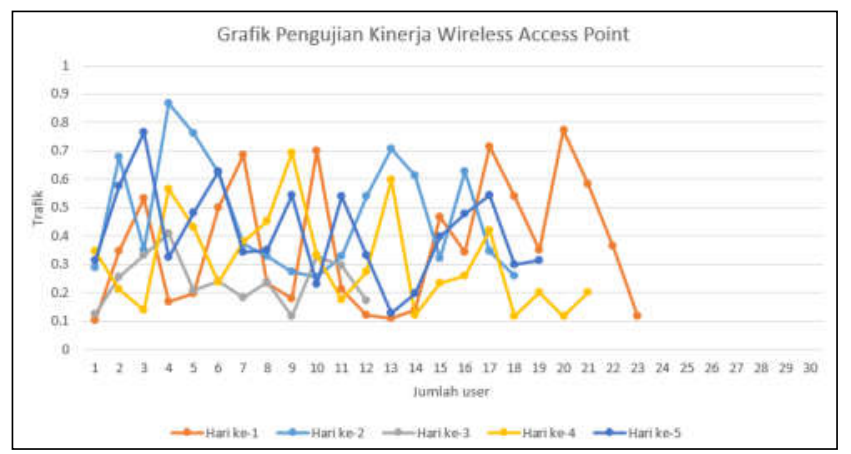

Gambar 7 Grafik Pengujian Kinerja Wireless Access Point 
Dari grafik dalam Gambar 7 dapat dilihat bahwa terdapat perbedaan jumlah user yang terhubung dengan WAP selama 5 hari pengambilan data. Sebanyak 9 user aktif yang menggunakan trafik data tinggi di hari kelima sehingga hanya 14 user yang dapat terhubung dengan WAP. Sedangkan dihari ketiga hanya 3 user yang menggunakan trafik data tinggi sehingga lebih banyak user yang dapat terhubung dengan WAP yakni sebanyak 23 user. Hal ini menunjukkan bahwa penggunaan trafik data oleh user mempengaruhi besar kemungkinan blocking oleh sistem yang dikarenakanjumlah user yang menggunakan trafik tinggi, sehingga sistem jenuh dan terjadi blocking pada user selanjutnya yang mencoba terhubung ke system. Berdasarkan Gambar 7 dapat dilihat bahwa dari 30 user yang dicoba disambungkan kepada WAP dalam 5 hari berturut turut, maksimal user yang bisa tertampung adalah 23 user dan yang lainnya tertolak

\section{KESIMPULAN}

Berdasarkan perencanaan, pengujian, hasil dan pembahasan maka dapat diambil kesimpulan bahwa mendesain program pada raspberry pi 3 untuk menjadi Wireless Access Point dengan ditambahkan sistem monitoring dapat bejalan dengan baik dimana ketika diujikan dengan 3 skema yaitu browsing, video stream, dan download dapat berjalan dengan lancar. Untuk skema browsing, WAP yang didesain dapat menampung 27 user. Sedangkan untuk skema video stream dan download, WAP yang dirancang hanya mampu menampung 17 user. Jumlah keduanya bisa sama dikarenakan dalam melakukan stream sebenarnya melakukan download untuk video tersebut tapi dalam bentuk video tidak seperti bentuk folder dalam download.

Mengukur kinerja raspberry pi 3 yang digunakan sebagai wireless access point berdasarkan jumlah user yang dilakukan selama 5 hari dapat berjalan dengan baik dimana jumlah user terbanyak didapat pada hari ke-5 dengan jumlah 23 user sedangkan jumlah user terkecil terjadi hari ke-3 dengan 12 user. Hal ini mungkin dikarenakan pada hari ke-3 WAP yang dirancang mengalami titik jenuh tertinggi (dikarenakan ada yang melakukan stream atau download) sehingga user yang bisa tergabung hanya sedikit.

\section{REFERENSI}

[1] Pengertian, Jenis, Fungsi dan Cara Kerja Router, "Situs Web", 24 Juni 2019. [Online]. Available: https://unbaja.ilearning.me/2015/11/18/pengertian-jenisfungsi-dan-cara-kerja-router/

[2] MySQL, "Situs Web", 24 Juni 2019. [Online]. Available: https://id.wikipedia.org/wiki/MySQL

[3] Pengertian dan Cara Kerja serta Fungsi Wireless Access Point, "Situs Web", 24 Juni 2019. [Online]. Available: https://blog.dimensidata.com/pengertian-dan-cara-kerjaserta-fungsi-wireless-access-point/

[4] Protokol Konfigurasi Host Dinamik, "Situs Web", 24 Juni $2019 . \quad$ [Online]. Available: https://id.wikipedia.org/wiki/Protokol_Konfigurasi_Hos_ Dinamik
[5] Rekayasa Trafik, "Situs Web", 25 Juni 2019. [Online]. Available: http://ekofajarcahyadi.dosen.ittelkompwt.ac.id/wpcontent/uploads/sites/10/2017/02/Pertemuan-9-BirthDeath-Process-Poisson-Model-Erlang-B-Model.pdf

[6] Khopkar, S. M. (1990). Konsep dasar Kimia Analitik. Jakarta: Universitas Indonesia. Indonesia Press.

[7] Datasheet Raspberry Pi 3 Model B

[8] Sumarya, DM(2013). Prediksi Kurs US Dollar terhadap Rupiah Menggunakan Metode Neural Network dengan Algoritma Backpropagation

[9] Grade of Service, "Situs Web", 26 Juni 2019. [Online]. Available: https://en.wikipedia.org/wiki/Grade_of_service

[10] Maximum Wi-Fi clients on Pi 3 hotspot,"Situs Web", 19 Nopember 2019. [Online]. Available: https://raspberrypi.stackexchange.com/questions/50162/ maximum-wi-fi-clients-on-pi-3-hotspot

[11] J. A. . Pratama, "Implementasi Keamanan Jaringan dengan Metode Whitelist pada Server Jurusan Elektro di Politeknik Negeri Malang”, Jaringan Telekomunikasi, vol. 8, no. 1, hlm. 56-61, Mar 2019.

[12] M. D. Ariyanto, A. W. Purwandi, dan M. A. Anshori, "Rancang Bangun Sistem Virtual Reality Nirkabel Berbasis WLAN", Jaringan Telekomunikasi, vol. 11, no. 3, hlm. 151-154, Sep 2021.

[13] N. Ferdiansyah dan N. . Suharto, "Komparasi Performasi Node Router Tengah dan Node Router Tepi pada Jaringan Manet menggunakan Protokol Olsr dan Batman”, Jaringan Telekomunikasi, vol. 9, no. 2, hlm. 1-10, Jun 2019.

[14]D. Priadi, "Pengukuran Quality of Service (QoS) Pada Aplikasi File Sharing dengan Metode Client Server Berbasis Android", Jaringan Telekomunikasi, vol. 6, no. 1, hlm. 39-49, Mei 2018.

[15]I. R. P. Jeinever, "Penerapan Sistem Keamanan Jaringan Menggunakan Random Port Knocking Berbasis Raspberry Pi yang Dikirim Melewati Telegram", Jaringan Telekomunikasi, vol. 7, no. 2, hlm. 61-67, Nov 2018. 